\title{
Surveying the Effectiveness of Dialectical Behavioral Therapy on Clinical Symptoms, Body Image, Self-Efficacy of People with Bulimia Disorder
}

\author{
FayyazSaberi Mohammad Hassan \\ B.A. in Clinical Psychology, Department of Psychological Sciences, Faculty of Humanities, Neyshabur Branch, \\ Islamic Azad University, Neyshabur, Iran \\ Email: Fsaberi@gmail.com \\ Toozandehjani Hassan* \\ Assistant Professor of psychology, Department of Psychological Sciences, Faculty of Humanities, Neyshabur Branch, \\ Islamic Azad University, Neyshabur, Iran \\ *Corresponding Author Email: H.Toozandehjani@ymail.com
}

\author{
Doi:10.5901/mjss.2016.v7n3s3p136
}

\begin{abstract}
This research is a semi-experimental research (pretest-posttest with control group) with the purpose of surveying the effectiveness of Dialectical Behavioral Therapy (DBT) on clinical symptoms, self-efficacy and body image of people with bulimia disorder. Statistical population of this study was women with bulimia disorder referred to nutrition clinics in Mashhad. The statistical sample of this research was 40 women with bulimia disorder chosen randomly by convenience sampling method and divided into two groups (20 women in experimental group and 20 women in control group), randomly. Applied tools were clinical symptoms questionnaire made by researcher, Sherer self-efficacy questionnaire and PSDQ (Physical Self-Description Questionnaire). For experimental group, Dialectical Behavior Therapy training sessions were held during 12 sessions, 75 minutes per session. During this time, control group didn't get any intervention. After the 12th session, research tools performed on subjects again, as posttest. The data of questionnaires were analyzed by descriptive statistic methods of mean and standard deviation, and Inferential statistics of covariance analysis. The results showed that the clinical symptoms of experimental group were decreased comparing to control group, and self-efficacy and self-descriptin were increased.
\end{abstract}

Keywords: Dialectical Behavioural Therapy, clinical symptoms, self-efficacy, body image, bulimia

\section{Introduction}

Eating disorders are syndromes in which cognitive changes related to food, body weight and bad-eating habits can cause threatening effects to life according to nutrition and medicin. Three types of eating disorders have been identified, including anorexia, bulimia and disorders with no special category (Stang J. ..Story M.). These disorders are shown in allsocial and economical categories and all nations (Muise A, Stein D, Arbess G). Eating disorder is the rifest psychiatric problem among young women and it causes a big number of death.

Eating disorder is identified, based on severe turmoil in eating behavior, and usually it is diagnosed in infancy or early childhood for the first time; like pica, ruminating disorder and infancy nutrition disorder that are placed in "feeding and eating disorders in infancy or childhood" part (Lindzy, Pavel; quoted from Yans and Nikkhoo, 2000).

Bulimia is rifer than anorexia, and its prevalence estimation is between 2 to 4 percent among young women. Its prevalence rate among women is 10 times much than men, but its start age at adolescence is later that start age of anorexia. Bulimia comparing to anorexia, causes less numbers of death, and its comparative or complete improvement rate is higher. The prevalence rate of this disorder in industrial countries is almost $1 \%$ of general population (Kaplan and Sadock's.2007. quoted from Rezaee). Bulimia is a mental disorder that is identified by eating a big amount of food in a short time and then purifying extra calories by vomiting or other extremist actions (Halgin RP, Whitborne SK, 2002).

According to DSM V, the main criteria for bulimia are: overeating periods that their frequency are rather high (at least once per week) and they last at least 3 months; Following compensatory behaviors in order to avoiding weight increasing, generally vomiting, bad consumption of laxatives, diuretics or vomiting drugs (10\%).

In 20\% cases, patientsturn into excessive exercises or strict diets as compensatory behavior; body weight is not as less as anorexia; patient has fear of being obese; he tends to lose weight continuously; self-valuation highly related to the 
shape and weight of body.

A lot of factors have role in bulimia, like clinical symptoms, self-efficacy and body image. People with bulimia suffering from weak self-esteem, disability feeling, inefficacy, lack of control on life, perfectionism, anxiety, depression, and anger. They show high-level of impulsiveness and negative image of their body (McCabe, M. P.,\& Vincent, M. A., 2003)

Evidences show that anxiety and depression in people with bulimia who are after clinical helps, are more, comparing to ordinary samples of population. Clinical symptoms with comorbidity with obesity in these people, like psychosis symptoms, body-dysmorphic disorder, major depression, suicidal tendency and eating disorders, are shown (Groth-Marnat, 1997).

Women with bulimia disorder, are more susceptible to anxiety and depression and other psycho-pathological symptoms, rather than men suffering from bulimia. Some researches have shown that prevalence of mental disorders like depression, anxiety disorders and binge eating disorder in people with bulimia are significantly higher comparing to ordinary people. Anyhow, it is not clear whether this comorbidity of mental disorders and obesity is because of a common reason or bulimia and metabolism disorders, have mental side effects and vice versa. Fairburn and colleagues (1998) in their studies showed that obese people with bulimia disorder, more likely used to suffer from negative self-valuation, parent's depression, major depression disorder, behavior problems and deliberately self-harming.

Another effective factor on bulimia, is self-efficacy. Self-efficacy is a constructing power that cognitive, social, emotional and behavioral skills are organized by it, to achieve various aims, in an effective way(Bandura, 1997). Selfefficacy believes increase functions of immune system; cause better physical health, flexibility in facing mental pressure, and result better social and mental adaptation. The growth of self-efficacy believes in special fields like job, sport, weight control, quit smoking and alcohol, and mental health problem consequences positive outcomes (Kar, A. 2006).

Body image is another effective factor on bulimia. Body self-concept has effects on the self-valuation feeling experienced in relationships; and it anticipate relationship satisfaction (Trzesniewskiand colleagues , 2009).

The researches made by Brown and colleagues (2009) showed that overweighting has negative effect on body self-concept. Overweight people experience intangible consequents of losing self-esteem, personal problems in social relationships, physical limitation and prejudice of family, friends staff and nurses and even strangers.

In fact, body image or body-self is formed by direct experience of body organs and status, and by social relationships. In social relationships ideals are shown as visible and invisible behaviors, and then get criteria for comparing one's real status with them.

After such comparison, individual feels satisfied or unsatisfied from his body (Bouricinco, translator: Behzad, 1999).Cach and Pruzinsky (2004) stated that face and body fitness assessment, body satisfaction and women's subjective impression are the components of body image that impact on women's dissatisfaction. Huang and colleagues' study (2009) showed that negative body image can cause unwanted social-mental impacts including anorexia or bulimia, depression, social anxiety, sexual dysfunction and reduction of self-confidence.

One of therapy methods that seems to be effective against bulimia, is dialectical behavioral theapy (DBT). This is a cognitive-behavioral therapy that basically is recognized by Marsha M. Linehanas a therapy for people attempting selfharming behaviors.

This cognitive behavioral therapy approach, at first was introduced for treating border line personality disorder (BPD). This approach, has mixed the interventions of CBT (that is based on change principle) with Eastern teachings and techniques (that are based on acceptance principle).According to this, he introduces four intermediary components: core mindfulness and distress tolerance as acceptance components and emotional regulation and interpersonal efficacy as change components (Wagner and colleagues,2007.quoted from Gharavi,2011).

Furthermore, as DBT was presented as a completely structured-therapeutic protocol and therapists could apply it more easily, it caused DBT to be used in a rather vast range of disorders, in addition to borderline personality disorder.

Evidences show that this approach in eating disorders treatment, especially binge eating disorder (Telch, Agras, Linehan, 2001;Feigenbaum, 2007), is effective. Cognitive-behavioral DBT therapy covers both cognitive disorders and behavioral abnormality aspects of people suffering from bulimia.

The purpose of cognitive-behavioral therapy is reducing over eating and purifying behaviors in people with bulimia, and changing their abnormal viewpoint about body shape and weight (Wilson, G.T., Fairburn, 1993). According to this viewpoint, bulimia continues because of disability in facing with unpleasant events, and proceeding inefficient thoughts and feelings about weight and body shape; and this cause overeating and purifying (Wilson, G.T., Fairburn, C. G., Agras, W. S., Walsh, B. T., \& Kraemer, H, 2002).

Researches have shown that DBT increases positive body image in people with bulimia (Telchand colleagues,2001;Vocks S, Wächter A, Wucherer M, Kosfelder J.2008). Furthermore, Denaro's researches (Denaro, J. L. 
,2007)have shown that in DBT, people learn that self-respecting occurs by interacting in a manner that individual feels eligibility and efficiency instead of inability; and their self-efficacy increases. Moreover Miller, A. M., Rathus, J. H., \& Linehan, M. m. (2007) stated that DBT purpose is increasing self-respect, achieving personal goals, solving deficiency feeling.

The necessity of this research is that in recent years, overweighting and bulimia have been widespread among nations. According to existing information, overweighting and bulimia have been a general and national problem in many countries, and that's why wide solutions are needed to encounter accurately and scientifically.

Specially overweighting and obesity, cause some problems like blood pressure, high blood fat, waist pain, asthma, live diseases, gallbladder, colon and rectum and prostate cancers in men, breast and ovary cancers in women, infertility problems in women, second type diabetes and finally increasing the risk of cardiovascular diseases and apoplexy.

Evidences show that comparing to ordinary samples of society, anxiety and depression in people with bulimia searching for clinical helps, are shown more. Furthermore, women with bulimia comparing to men with bulimia, are more susceptible to anxiety and depression and other mentally-pathological symptoms.

Totally, regarding daily growing bulimia in Iranian society and not paying attention to unwanted effects of overweighting, this research is after answering the question "Can DBT be useful in reducing clinical symptoms, increasing self-efficacy and positive body image of women with bulimia?".

\section{Method}

This research is a semi-experimental study (pretest-posttest with uneven control group) that aimed to survey the effectiveness of DBT training on clinical symptoms, self-efficacy and body image of women with bulimia. Statistical population of this study was women with bulimia disorder referred to nutrition clinics in Mashhad (regions: Ferdowsi Blvd., Sajjad, Azadshahr, Ahmadabad). The statistical sample of this research was 40 women with bulimia disorder chosen randomly by convenience sampling method, after getting sure that they have bulimia (by performing Ahwaz Eating Disorder Scale) and then divided into two groups (20 women in experimental group and 20 women in control group), randomly. Entrance criteria were: female gender at the age between 18 to 25; not allowing to participate in other therapeutic plans during DBT therapy; consciously consent for participating in the plan; having sufficient interest and motivation for regular participating and cooperating in training sessions; commitment for homework. Exit criteria were: participating in other therapeutic programs simultaneously; more than on session absence; lack of commitment for homework.

\subsection{Research tools}

Clinical symptoms questionnaire: This researcher-made questionnaire has 16 questions that assesses mental disorders with comorbidity with obesity, like major depression, suicidal tendency, the symptoms of psychosis, dysmorphic disorder. Each component has 4 questions. Scoring conditions are: "never": 0, "sometimes": 1, "often": 2, "always": 3. Reliability of this questionnaire has been confirmed by specialists and masters in this field. Reliability specifies how accurately an assessing tool evaluates a feature. Without awareness of the reliability of assessing tools, there is no certainty that its data is accurate. For measuring the reliability of this questionnaire, Cronbach's alpha is used. For this purpose, a pilot has been done on 30 subjects and Cronbach's alpha coefficient was calculated by SPSS and it was $77 \%$ for whole test that means high reliability.

Sherer self-efficacy questionnaire: this scale has 17 questions and each question is in the range of "completely disagree" to "completely agree" in Likert scale. For scoring, each question gets a score between 1 to 5 . Questions $1,3,8,9,13$ and 15 are scored from left to right (in the questionnaire in Persian) and the others vise versa. Thus, the maximum score one can get from this scale is 85 and the least score is 17 . This scale has been translated and validated by Barati (1998).

Physical Self Description Questionnaire (PSDQ): This scale has 47 questions and each one has 6 options in Likert scale. Questions 8,11,17,19,22,25,29, 30, 33, 39, 46, 47 are scored conversely. Rismanchian, Golparvar and Kamkar (2007), calculated alpha coefficient in the range of 17 to 79 years old as below: in physical activities, coordination, and tolerance, 0.89 ; appearance, flexibility and health, 0.88 ; in body fat and overall body self-concept, 0.90 ; in sport 0.94 ; in power, 0.92 ; and overall self-esteem 0.77 . The results of this analysis support the structured validation of body selfconcept and other important components of it. Totally, alpha coefficient was 0.80 .

DBT plan performing is based on Linehan's work (2008) and was programmed by Salbach-Andrae $\mathrm{H}$, and colleagues (2008) that was 12 sessions, once per week, 75 minutes each session. 
First session, introductive explanations, problem conceptualization, preparing referees and performing pretest, training the skills of distracting from self-harming behaviors and enlisting pleasurable activities as replacing it in weekly schedule.

Sessions 2,3 (mindfulness training): emotional awareness and wisely awareness, training about the skills are visible and describable and about how they are not judged, stay focused, how work.

Sessions 4,5: training of distress tolerance skills, stability in crisis skills, distraction, self-relaxing using six senses and awareness training.

Sessions 6,7 (how to deal with food and body image): eating training, balance eating, various nutrition, reducing negative thoughts and fundamental believes about body and eating, increasing attractiveness and positive body experiences.

Sessions 8,9 (emotional regulation): The aims of emotional regulation is knowing why emotions are important; emotion recognition, reducing vulnerability and emotional pain, increasing positive emotion, feeling changing by acting contrary to current affect.

Sessions 10,11 (increasing interpersonal self-efficacy): keeping and maintaining relationships health, intrests, etc. training important personal skills like description, assertiveness, confidence, negotiate and self-esteem.

Session 12: summarizing the sessions and reviewing and practicing training sessions context; Finally, posttest was done. The data of research were analyzed by descriptive statistics methods for mean and standard deviation, and by Inferential statistics for covariance analysis.

\section{Findings}

The mean and deviation of age in experimental group was 16.60 and 2.22, and in control group was 21.50 and 2.21 in the range of 18 to 25 years old.

Table 1 presents comparing mean and deviation of variables score in pretest and posttest in both experimental and control group.

Table 1:

\begin{tabular}{|c|c|c|c|c|c|c|c|c|}
\hline \multirow{2}{*}{ Situation } & \multicolumn{4}{|c|}{ Experimental group } & \multicolumn{4}{|c|}{ Control group } \\
\hline & & Pretest & & Posttest & & Pretest & & Posttest \\
\hline Variables & Mean & Standard deviation & Mean & Standard deviation & Mean & Standard deviation & Mean & Standard deviation \\
\hline \multirow{5}{*}{ 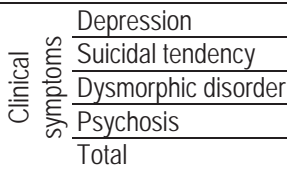 } & 8.5 & 1.79 & 5.4 & 1.76 & 8.60 & 1.64 & 8.45 & 1.96 \\
\hline & 7.5 & 1.99 & 4.10 & 1.68 & 7.4 & 1.57 & 7.53 & 1.79 \\
\hline & 9.15 & 1.90 & 4.70 & 1.75 & 9.20 & 1.61 & 9.40 & 1.35 \\
\hline & 9.35 & 1.39 & 4.50 & 1.57 & 9.45 & 1.43 & 9.30 & 1.63 \\
\hline & 34.50 & 6.36 & 18.70 & 6.00 & 34.65 & 5.43 & 34.50 & 5.42 \\
\hline Self-efficacy & 38.60 & 8.79 & 43.35 & 9.42 & 37.70 & 8.69 & 35.80 & 11.38 \\
\hline Body image & 143 & 17.51 & 150.50 & 17.03 & 142.90 & 18.04 & 142.75 & 142.90 \\
\hline
\end{tabular}

Table 2 is Lons $\mathrm{F}$ test for the homogeneity assumption of variances of experimental group and control group in pretest. As it's shown, lonz's $\mathrm{F}$ for these variables is not significant. Therefore homogeneity assumption of variances of experimental group and control group is observed; it means there is no significant differences between the variance of scores of clinical symptoms, self-efficacy, body image in pretest. This researcher's assumption (homogeneity of variances in pretest of both groups) is confirmed, and researcher can start training the experimental group, in peace of mind.

To survey the effectiveness of DBT intervention, covariance analysis test was used. The result of covariance analysis, the effects of DBT intervention on reducing clinical symptoms, self-efficacy in positive body image increasing in women with bulimia are presented in Table2.

Table 2:

\begin{tabular}{lccccccc}
\hline Resource/index & SS & df & MS & F & Significant level & Effect rate & Statistical power \\
\hline Clinical symptoms & 2453.24 & 1 & 2452.24 & 901.326 & 0.000 & 0.96 & 1.000 \\
\hline Self-efficacy & 442.53 & 1 & 442.53 & 12.41 & 0.001 & 0.25 & 0.93 \\
\hline Body image & 585.53 & 1 & 585.53 & 110.161 & 0.000 & 0.75 & 1.000 \\
\hline
\end{tabular}


As it is shown in table2, $\mathrm{F}$ value resulted from covariance analysis, $\mathrm{P}<0.05$ is significant after deleting pretest effect. Therefore, with the possibility of 95\% DBT training had been effective on clinical symptoms, self-efficacy and body image of women with bulimia.

The effect of this therapeutic intervention on clinical symptoms was 0.96 , on self-efficacy was 0.25 and on body image was 0.75 . It means $96 \%$ of personal differences in posttest scores of clinical symptoms, $25 \%$ of personal differences in posttest scores of self-efficacy, $75 \%$ of personal differences in posttest scores of body image are because of DBT effect. Score 1 in statistical power in clinical symptoms and body image means that there was no possibility for error type 2, and statistical accuracy is high. Score 0.93 in statistical power in self-efficacy means that if this research repeats 1000 times, just 25 times it is possible that null hypothesis= 0.93 gets confirmed.

\section{Discussion and Conclusion}

Current research has been done by the aim of surveying the effectiveness of DBT on clinical symptoms, self-efficacy and body image in women with bulimia. Research findings shows that DBT has caused reduction of clinical symptoms of experimental group's subjects, comparing to control group. These results of this research are like the results of previous researches such as Robins CJ, Koons CR.(2010) and Safer DL, James L. (2007) and Kenz and colleagues (2004; quoted fromFeigenbaum,2007) and Linehan and colleagues (1986; quoted from Chu, 2006).

Obese people with bulimia, more likely were suffering from negative self-assessing, depression, major depression disorder, behavioral problems and self-harming, in their childhood and adolescence (Fairburn and colleagues, 1998). Researches done by Mc Keeb and Winst (2003) showed that these people suffer from anxiety, depression, hostility and anger. Moreover, in these people unpleasant experiences and negative perception of body shape and size are more. They have high level of impulsivity. Some scholars place bulimia as a subgroup of depression disorder (Cooper,P.J., \& Fairburn,C.G.,1986), Hinz, L.D. \&Williamson, D.A. (1987).

According to the finding of this research, DBT training causes reducing clinical symptoms like psychosis, body dysmorphic, depression and suicidal tendency. Furthermore, it is effective in eating disorder treatment. These findings are aligned with the findings of Croucher, Eschi Winger, Fledman (2010), quoted from Babayi and colleagues (2012). Sometimes affects like depression, anxiety, fear and their derivatives like feeling guilty and shame arise and get that much severe that normal psychological defenses tangle. Therefore, those severe affections express by physiological processes, and instead of mental pain, his body organs get pain, and unpleasant affection appears physically and its mental part goes to unconscious.

The reason of reducing clinical symptoms is the content of DBT sessions. DBT has impressive impact in reducing the symptoms of depression. This treatment cause reducing the symptoms of bulimia, by impacting on behavior (Robins CJ, Koons CR.2010).

DBT increases the ability of peoples with bulimia in achieving positive results, significantly, by teaching effective coping skills; and facilitates reducing maladaptive behaviors. Moreover, DBT causes depression reduction by providing emotion-focused coping strategies such as providing appropriate emotional responses to depression, blaming, etc. that are used to adjust the situation. This is aligned withSalbach-Andrae and colleagues' researches (2008). All these skills cause reducing bulimia and its clinical symptoms in people suffering from bulimia.

Furthermore, in this research it has been shown that DBT is effective on efficacy of women with bulimia; this results are aligned with Wilson's results (2004) and Mata's result (2009). In DBT sessions, by teaching skills and replacing inefficient and maladaptive behaviors by logical and targeted answers, people's self-efficacy level increases.

In this method, individuals learn how to regulate emotions. Moreover, the therapist changes individuals perception, by changing their behavior, motivation level, thought patterns and emotional reactions. This change is an effective factor on acceptance, maintaining and changing behavior related to a wide range of required behaviors in reducing bulimia, and consequently causes increasing their self-efficacy.

According to this finding and previous finding, the hypothesis can be explained that one of the important factors in the formation of bulimia is body image disorder, and so, DBT can be effective on positive viewpoint of body and improvement of body images; that is applying cognitive methods to improve intellectual distortion, body image believes, cognitive errors, how to cope with these cognitions, coping techniques like relaxation, emotional regulation training. Furthermore, in therapeutic sessions, individual's ability for achieving positive results and reducing maladaptive behaviors increases, significantly, by increasing his functions via new skills, and increasing his motivation to use these skills and generalizing them and placing them in his behavior treasury (Linehan,1993; quoted from Chu,2006).

Moreover, DBT uses behavioral techniques such as imaginary and real encountering to adjust negative body image. In applying encountering using systematic desensitization, referee is taught to encounter those parts of body 
causing inconvenience, gradually, using relaxation techniques, and then to decrease their tension, inconvenience and anxiety; and then to receive the feeling of satisfaction and completeness.

Therefore, DBT cause correction and decreasing negative body image via cognitive and emotional strategies, and in consequence creates positive body image. Our country (IRAN) has the youngest population in the world, So that more than 50 percent of its population are children and adolescents and the youth. This young population is a property for developing purposes.

Eating disorders threats adolescents' general health. Bulimia and anorexia have an important role in the deaths because of psychiatric disorders. However, in the case of insufficient attention to adolescents' health, who suffering from bulimia, eating disorders appears in the form of abnormal behaviors, because of lack of physical health and consequently lack of mental health.

This issue will have huge personal and social impacts on their present and future, and their mental health. Therefore, according to this research results, by using DBT training, we can impact on clinical symptoms, self-efficacy and body image of women with bulimia, and consequently on the mental health of the youth and adolescents suffering from eating disorders.

Doing this research among women with bulimia, decreases the generalizability of the results. Subsequent researchers are recommended doing this research in other societies and compare the results with each other; and doing this research in people with other disorders such as anorexia nervosa; and doing this research in a wider range of age. A recommendation for psychologists and counselors, in addition to setting aims, is preparing training handbook of DBT for psychologists and nutrition clinics to use for people with bulimia.

\section{References}

Babayi, Z. Hassani, J. Mohammadkhani, Sh. (2012). The effect of emotional regulation of DBT on temptation of drug-addicted people: case study.Clinical psychology journal, (3).

Bourisinco,J. the aspects of a woman's life. Translator Behzad,M.(2000). 1sted.Tehran: Tootia

Sadouk,BJ. Sadouk,VA.(2010). Summary of psychiatry: Behavioral sciences/Clinical psychiatry.translator Rezaee,F. $3^{\text {rd }}$ ed.Tehran: Arjmand.2000.

Gharavi,M.(2011). The efficiency of group DBT on depressive symptoms in university students focusing on core mindfulness, stress tolerance, emotional regulation. Translator Rezaee, F. Mental health principles. 13(20).2000. 35-124.

Kar, A. positive psychology the knowledge of human's happiness and power. Translator: Sharififar, P. Najafizand,J. Sanayi, B. Tehran: Sokhan.2004.

Bandura,Albert.(1997) Self-efficacy: the exercise of control. New York: W. HFreeman.

Brown , M, Z.Linehan , M, M. Comtais , K, A , Murray A.Champan A.L(2009). Self-concept as prospective predictor of self - inflicted injury in border line personality disorder . A multi -modal analysis. Behavior Research and Therapy $47,815-822$.

Cash, T.F; Pruzinsky, T. (2004) Body images, Development, Deviance, and Change. The Guilford press- New York- London.

Chew, C. E (2006). The effect of dialectical behavioral therapy on moderately depressed adults: A multiple baseline design. PhD thesis, University of Denver, USA.

Claes, L., Vandereycken, W., Vertommen, H. . (2003). Eating-disordered patients with and without self-injurious behaviors: a comparison of psychopathological features. Eur Eat Disord, 11:379 -96

Cooper, P. J.,\&Fairburn, C. G. (1986). Depressive symptoms of bulimia nervosa. British Journal of Psychiatry, 148, 268-274

Denaro, J. L. (2007). Effectiveness of dialectical behavior therapy in treatment of adolescent girls with borderline personality features in an outpatient community mental helth setting. PhD thesis, University of Hartford, USA.

Delinsky SS, Wilson GT.(2010)Cognitive BehaviorTherapy With Body Image Exposure for BulimiaNervosa: A Case Example. Cogn \& Behav Pract. (17): 270-277.

Fairburn CG, Doll HA, Welch SL, Hay PJ, Davies BA, OConnor ME( 1998). Risk factors for binge eating disorder:A community based case-control study. Arch Gen Psychiatr:;55:425-32.

Feigenbaum, J. (2007). Dialectical behavior therapy: An increasing evidence base. Journal of mental helth, 16(1), 51-68.

Groth-Marnat, G. (1997). Handbook of psychologicalassessment (9th. ed). New York: John Wiley \& Sons

Halgin RP, Whitborne SK(2003). Abnormal Psychology: Clinical Perspectives on Psychological Disorder 4th ed. New Yourk, McGrawHill.

Hinz, L.D.,\&Williamson, D.A. (1987). Bulimia and depression:Areviewof the affective variant hypothesis. Psychological Bulletin, 102, 150158

Huang AJ, Stewart AL, Hernandez AL, Shen H, Subak LL.(2009)Sexual function among overweight and obesewomen with urinary incontinence in a randomized controlled trial of an intensive behavioral weight lossintervention. J Urol May;181(5):2235-42.

Mata J, et al.(2004). Motivational "Spill-Over" DuringWeight Control: Increased Self-Determination and disorders: Theory and practice. Philadelphia: Wileyand sons .

McCabe,M.P., Vincent,M.A.(2003).The role of bio-developmental and psychological factors in disordered eating among adolescent males and females. European Eating Disorders Review315-328. 
Muise A, Stein D, Arbess G.( .2003). Eating disorder in adolescent boys: A review of the adolescent andyoung adult literature. Journal of adolescent health; 33: 427-435.

Miller, A. M., Rathus, J. H., \& Linehan, M. m. (2007). Dialectical behavior therapy with suicidal adolescents.Gilford press.

Nazart, M., mirza, D., yanvoski, J.A.(2005). Body dissatisfaction, self esteem, and orewight among inner-city Hispanic children and adolescent, Journal of Adolescent Health, 36,267,270.

Robins CJ, Koons CR. (2010) Dialectical behaviortherapy of sever personality disordersMagnavita JJ. (editor). Handbook of personality eating. [Dissertation]. Appalachian State University

Safer DL, James L. (2007).Dialectical Behavior Therapy Modified for dolescent Binge EatingDisorder: A Case Report. Cogn \& Beha Prac. (14): 157-167.

Salbach-Andrae H, Bohnekamp I, Pfeiffer E, Lehmkuhl U.( 2008) Dialectical Behavior Therapy ofAnorexia and Bulimia Nervosa Among Adolescents: A Case Series. Cogn \& Behav Pract.; 15: 415-425.

Stang J, Story M. (2005). Guideline for adolescent nutrition services;155-156[online]http://wwww.epi.umn.edu/let/pubs/adol-book.shtm.

Telch CF, Agras WS, Linehan MM. (2001). Dialectical behavior therapy for binge eating disorder. J Consul \& Clin Psychol.; (69): 10611065.

Trzesniewski, K. H, Donnellan, M. B., Moffit, T. E., Robins, R. W, Poulton, R., \& Caspi, A. (2009). Deficit in self concept during adolescence predicts poor health, criminal behavior, and limited economic prospects during adulthood. Development Psychology, 42, 381-390.

Vocks S, Wächter A, Wucherer M, Kosfelder J. (2008). Look at yourself: Can body image therapy affectthe cognitive and emotional response to seeingoneself in the mirror in eating disorders? Eur EatDisord Rev; (16): 147-154.

Wilson GT. (2004). Acceptance and change in thetreatment of eating disorders: The evolution ofmanual-based cognitive-behavioral therapy. In S. C.Hayes, V. M. Follette, \& M. M. Linehan (Eds.), Mindfulness and acceptance: Expanding thecognitive-behavioral tradition. New York: Guilford Press.

Wilson, G.T., \& Fairburn, C. G. (1993). Cognitive treatments for eating disorders. Journal of Consulting and Clinical Psychology, 61, 261-269.

Wilson, G.T., Fairburn, C. G., Agras, W. S., Walsh, B. T., \& Kraemer, H. (2002). Cognitive- $\quad$ behavioral therapy for bulimia nervosa: Time course and mechanisms of change. Journal ofConsulting and Clinical Psychology, 70, 267-274. 